\title{
Неклассические дифракционные решетки на выставке Laser World of Photonics 2019
}

\author{
А.Н. Мельников ${ }^{1}$, Н. Л. Истомина ${ }^{2}$ \\ 1 АО «Швабе», АО «НПО ГИПО», gipo@telebit.ru, Казань, Россия \\ 2 АО «РИЦ «ТЕХНОСФЕРА», www.photonics.su, Москва, Россия
}

\begin{abstract}
Успехи лазерной оптики сверхмощных и ультракоротких импульсов придали новое дыхание технологиям создания дифракционных решеток, которые являются важнейшими подсистемами линий задержки с противоположными дисперсиями. Все чаще дифракционные решетки привлекают к себе внимание конструкторов оптико-электронных приборов. Об этом свидетельствует расширение сегмента продукции дифракционных решеток в экспозиции выставки Laser World of Photonics 2019 (Messe München, Мюнхен, Германия).
\end{abstract}

Ключевые слова: вогнутые дифракционные решетки, DO-объективы, гризмы

\section{Non-Classic Diffraction Gratings at the Exhibition Laser World of Photonics 2019}

\author{
A. N. Melnikov ${ }^{1}$, N. L. Istomina ${ }^{2}$ \\ I Shvabe JSC, "NPO «State Institute of Applied Optics», GIPO JSC, gipo@telebit.ru, Kazan, Russia \\ 2 APC TECHNOSPHERA JSC, www.photonics.su, Moscow, Russia
}

\begin{abstract}
The success of laser optics of ultra-high-power and ultra-short pulses has given new breath to technologies for creating diffraction gratings, which are the most important subsystems of delay lines with opposite dispersions. Increasingly, diffraction gratings attract the attention of designers of optoelectronic devices. This is evidenced by the expansion of the diffraction grating product segment at the exposition of the Laser World of Photonics 2019 exhibition (Messe München, Munich, Germany).
\end{abstract}

Key words: concave diffraction gratings, DO lenses, grisms

Если раньше в таких оптических элементах, как дифракционные решетки, нуждались только создатели спектрометров и лазеров, а также метрологические службы, и объем производимой продукции был ограничен специализированными заказчиками, то с развитием гиперспектральной съемки, VR/AR-технологий, потребительской спектрометрии, телекоммуникацинных систем картина рынка резко изменилась. Сегмент продукции дифракционных решеток в экспозиции выставки Laser World of Photonics 2019 (Мюнхен, Германия) заметно вырос.
Хотя основы технологии создания дифракционных решеток известны всем (это либо нарезные, либо голограммные решетки), но каждая компания сохраняет в тайне конкретное оборудование и конкретный метод создания решеток. И нарезные, и голограммные решетки, как правило, представляются в виде реплик с оригинальных решеток. Голограммные решетки обладают меньшим светорассеянием, нарезные имеют более высокую дифракционную эффективность.

Системы с кросскорреляционными спектрометрами, построенными по схеме Черни-Тернера 
(Crossed Czerny-Turner - CCT), со спектрометрами с пропускающими решетками (Transmission Grating based Spectrometer - TGS), построенные по схеме "линза-решетка-линза" (LensGrating-Lens) или по схеме "зеркало-решетка-зеркало" (MirrorGratingMirror - MGM), - все они нуждаются в снижении массо-габаритных характеристик при оптимальном выборе высокого спектрального разрешения и высокой оптической силы. Для максимального сбора световой мощности от образца без эффекта перекрытия диспергирующих лучей конструкторы используют конфигурацию LGL. Для достижения высокого разрешения разработчики предпочитают конфигурацию MGM. Зеркала и линзы, фокусирующие дифракционные максимумы на детекторы в виде линейных матриц, могут быть заменены вогнутыми дифракционными решетками (concave diffraction gratings - CDG). CDG обладают способностями как диспергирующих, так и фокусирующих оптических элементов. Это позволяет минимизировать количество элементов в оптических схемах спектральных приборов, и, следовательно, уменьшать массогабаритные характеристики этих приборов, и увеличивать отношение "полезный сигнал/фон".

Классические CDG изготавливаются на подложках с рабочими сферическими поверхностями [1]. Проекции их штрихов на плоскость, касательную к поверхности решетки в ее центре, - это эквидистантно расположенные друг от друга прямые линии. Их главный недостаток - это аберрация типа «астигматизм", которая уменьшает реальную светосилу и разрешающую способность CDG. Для компенсации астигматизма сферической CDG используются три способа:

- изменение ее шага по определенному закону (изготовление штрихов с переменным шагом);

- формирование непрямолинейных штрихов;

- комбинация первых двух способов.

Аберрационно-скорректированные CDG изготавливаются как с помощью голографической технологии, так и нарезной технологии (при помощи делительных машин с интерференционным управлением) [1]. Если у голограммных CDG закон изменения шага и непрямолинейности их штрихов зависит от расположения записывающих когерентных источников относительно подложки решетки [2], то у нарезных CDG коррекция обеспечивается выбором соотношения между величиной подачи подложки решетки и динамикой движения алмазного резца.

Полная цитата из работы [1] говорит, что требования к закону изменения шага стигматической

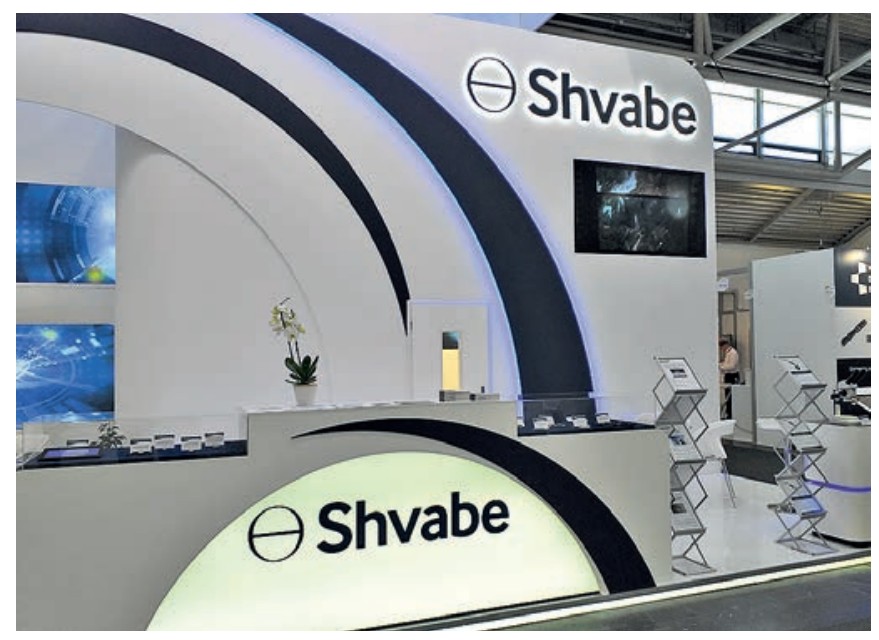

решетки и к форме штрихов могут быть получены из условий интерференции сферических волн, исходящих из двух точечных когерентных источников. В результате интерференции образуется система стоячих волн с поверхностями равной фазы, которые удовлетворяют условию $r_{1}-r_{2}=n \lambda$, где $r_{1}$ и $r_{2}-$ расстояния от данной точки пространства до когерентных источников, $\lambda$ - длина волны записи, $n$ - целое число. Эти поверхности представляют собой семейство двухполостных гиперболоидов вращения, для которых источники являются полюсами, а оси вращения проходят через эти точки.

Штрихи стигматической CDG получаются путем пересечения указанного семейства гиперболоидов со сферической поверхностью подложки решетки и при произвольном расположении источников относительно подложки решетки являются непрямолинейными и неэквидистнантными. CDG могут изготавливаться на поверхностях различных форм, однако для обеспечения минимальных аберраций при удалении от стигматической точки предпочтительно использовать поверхности, образованные вращением кривых второго порядка.

В случае, когда решетка наносится на сферическую поверхность, задача несколько упрощается, если один из источников лежит в центре ее кривизны, а второй - в произвольно расположенной точке. Тогда в проекции на плоскость, касательную к поверхности подложки в ее центре, штрихи такой решетки при произвольном расположении второй стигматической точки имеют форму эллипсов переменной кривизны, расстояния между которыми, т.е. шаг решетки, изменяются по закону арифметической прогрессии. Радиус кривизны штрихов и степень непостоянства шага определяются положением второй стигматической точки. Если она лежит на конечном расстоянии на прямой, касательной к окружности Роуланда в центре кривизны 
подложки, то штрихи представляют собой прямые линии, расстояние между которыми изменяется по закону арифметической прогрессии. В том случае, когда вторая стигматическая точка расположена на окружности Роуланда, шаг решетки постоянный, а штрихи имеют форму эллипсов с радиусом кривизны в центре решетки, равным r=Rctg $\gamma$, где $\mathrm{R}$ - радиус кривизны рабочей сферической поверхности решетки, $\gamma$ - угол дифракции для стигматической точки.

Как отмечается в [2], наибольшими коррекционными возможностями обладают вогнутые неклассические нарезные CDG, имеющие искривленные штрихи и неэквидистантный шаг нарезки, вогнутые голограммные CDG. Астигматизм CDG позволяет исправить дифракционная решетка с криволинейными штрихами и постоянным шагом нарезки. Такая CDG образуется пересечением сферической поверхности круговыми цилиндрами, отстоящими друг от друга на одинаковое расстояние $e_{0}$, причем закон изменения радиуса кривизны штрихов определяется как $\rho(\gamma)=\rho_{0}-\rho \gamma$, где $\rho_{0}-$ радиус кривизны штриха в его вершине. Получены условия полной компенсации астигматизма в установках на круге Роуланда.

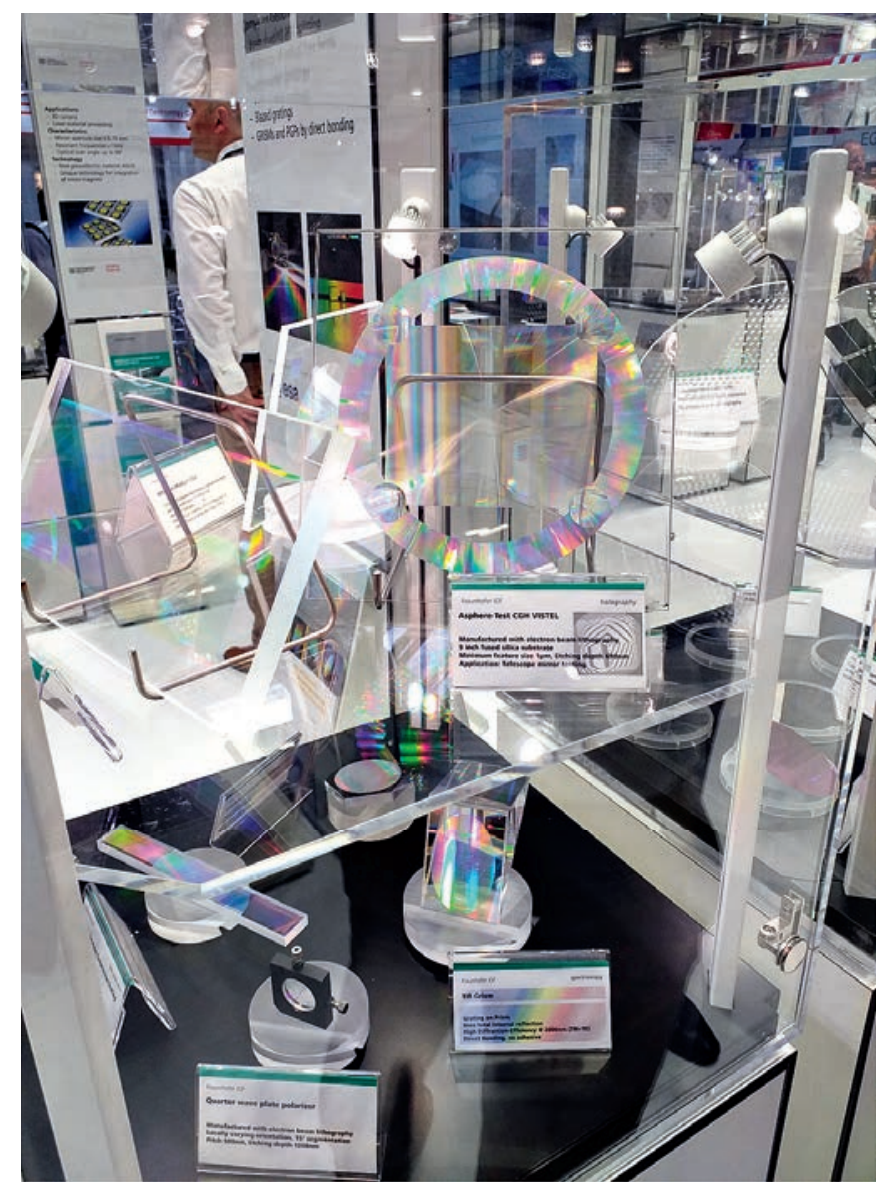

У решеток с концентрическими штрихами $(\rho=1)$ в определенных случаях вместе с астигматизмом устраняется и кома 2-го порядка. У сферических решеток со штрихами, образованными параллельными плоскостями, расстояния между которыми меняются по закону

$$
e=e_{0}\left(1+\mu_{1} \gamma+\mu_{2} \gamma^{2}+\ldots\right)
$$

где $\mu_{1}, \mu_{2}, \mu_{i}, \ldots$ - коэффициенты неравномерности шага, при выполнении определенных условий можно получить исправление астигматизма для одной, двух или трех длин волн. Можно найти такой закон изменения шага, при котором исправляются не только астигматизм, но и остальные аберрации. Так, решетка с прямолинейными штрихами дает безаберрационное изображение точки щели, если эта точка и ее монохроматическое изображение для заданного угла дифракции находятся на заданной прямой, проходящей через центр кривизны решетки, а шаг нарезки определяется законом, при некоторых допущениях принимающим вид

$$
f(\gamma)=\left(1+2 \mu_{1} \gamma\right)^{1 / 2}
$$

Подобная CDG имеет три стигматические точки, что позволяет ее использовать для решения тех задач спектроскопии, когда требуется высокое разрешение в узкой спектральной области.

Hа Международной выставке Laser World of Photonics 2019 в продуктовой нише голограммных CDG с коррекцией аберраций выступили известные компании (разработчики и изготовители):

- холдинг АО «Швабе» / АО «НПО ГИПО» (http://shvabe.com/about/company/ gosudarstvennyy-institut-prikladnoy-optiki/ produktsiya-gipo/opticheskie-materialy);

- корпорация "HORIBA Jobin Yvon Ltd." (http:// www.horiba.com/scientific/products/diffractiongratings);

- компания Carl Zeiss Microscopy GmbH (http://www.zeiss.de/gratings);

- компания "Shimadzu Corporation" (http://www.shimadzu.com/opt);

- компания Newport (http://www.gratinglab.com). Параметры голограммных CDG пяти фирм приведены в работе [3].

Другая область современной техники, нуждающаяся в дифракционных элементах - VR/AR-системы. При проектировании VR/AR-yстройств гибридные объективы с цифровой линзой, т.е. объективы с использованием 
Таблица. Сравнительные технические характеристики поставляемых гризм

\begin{tabular}{|c|c|c|c|c|c|}
\hline \multirow{2}{*}{$\begin{array}{l}\text { Параметры поставляемых } \\
\text { гризм }\end{array}$} & \multicolumn{5}{|c|}{ Фирмы-изготовители } \\
\hline & $\begin{array}{l}\text { АО «НПО } \\
\text { ГИПО» } \\
\text { (Россия) }\end{array}$ & $\begin{array}{l}\text { Fraunhofer IOF } \\
\text { (Германия) }\end{array}$ & $\begin{array}{c}\text { Wasatch } \\
\text { Photonics (США) }\end{array}$ & $\begin{array}{c}\text { Carl Zeiss } \\
\text { Spectroscopy } \\
\text { GmbH } \\
\text { (Германия) }\end{array}$ & $\begin{array}{l}\text { HORIBA France } \\
\text { SAS (Япония- } \\
\text { Франция) }\end{array}$ \\
\hline $\begin{array}{l}\text { Рабочий спектральный } \\
\text { диапазон }\end{array}$ & $\begin{array}{l}\text { видимый- } \\
\text { ближний ИК }\end{array}$ & $\begin{array}{c}\text { УФ-средний } \\
\text { ИК }\end{array}$ & $\begin{array}{l}\text { видимый- } \\
\text { ближний ИК }\end{array}$ & 115 HM - 30 мкм & $\begin{array}{l}\text { видимый- } \\
\text { ближний ИК }\end{array}$ \\
\hline $\begin{array}{l}\text { Дифракционная } \\
\text { эффективность, \% }\end{array}$ & более 85 & $90-95$ & более 85 & более 85 & высокая \\
\hline $\begin{array}{l}\text { Тип пропускающей } \\
\text { дифракционной решетки }\end{array}$ & $\begin{array}{c}\text { голограммная, } \\
\text { объемно- } \\
\text { фазовая }\end{array}$ & $\begin{array}{c}\text { фотолитогра- } \\
\text { фическая, } \\
\text { бинарная } \\
\text { рельефно- } \\
\text { фазовая }\end{array}$ & $\begin{array}{c}\text { голограммная, } \\
\text { объемно- } \\
\text { фазовая }\end{array}$ & $\begin{array}{c}\text { нарезная } \\
\text { суглом } \\
\text { "блеска" или ее } \\
\text { реплика }\end{array}$ & $\begin{array}{c}\text { голограммная, } \\
\text { рельефно- } \\
\text { фазовая }\end{array}$ \\
\hline $\begin{array}{l}\text { Оптический материал } \\
\text { подложек }\end{array}$ & $\begin{array}{c}\text { кварцевое } \\
\text { оптическое } \\
\text { стекло }\end{array}$ & $\begin{array}{c}\text { кварцевое } \\
\text { оптическое } \\
\text { стекло }\end{array}$ & $\begin{array}{c}\text { кварцевое } \\
\text { оптическое } \\
\text { стекло }\end{array}$ & $\begin{array}{c}\text { в зависимости } \\
\text { от рабочего } \\
\text { спектрального } \\
\text { диапазона }\end{array}$ & $\begin{array}{l}\text { кварцевое } \\
\text { оптическое } \\
\text { стекло }\end{array}$ \\
\hline Габариты, мм & до $70 \times 70 \times 20$ & до $200 \times 120 \times 65$ & по запросу & по запросу & $\begin{array}{c}\text { до } \\
500 \times 500 \times 100\end{array}$ \\
\hline $\begin{array}{l}\text { Точность юстировки взаим- } \\
\text { ного положения соединяемых } \\
\text { призм (клиньев), угл. мин. }\end{array}$ & не более 1,0 & менее 1,0 & - & по запросу & - \\
\hline
\end{tabular}

цифрового алгоритма коррекции оптических аберраций изображения, не обеспечивают у пользователей чувства эффекта присутствия. Для этих задач разрабатываются DO-объективы - линзы, соединенные с дифракционной решеткой. Научный конгресс, проходивший параллельно с выставкой, включал в себя семь суб-конференций. В их число вошла конференция "Цифровые оптические технологии", где на пленарных сессиях обсуждались в ряду прочих вопросов новые оптические схемы и элементы для VR/AR-систем, вычислительной оптики для отображения и визуализации, в том числе обсуждались DO-объективы и "гризмы".

Гризмы - гибридные (рефракционно-дифракционные) оптические компоненты, состоящие из оптических элементов - дифракционных решеток и призм. Поэтому термин "гризма" (от анг. "grism") образован в результате сочетания слов "GRating" - "дифракционная решетка" и "prISM" - "призма". Область применения гризм - астрономические спектрометры и системы телекоммуникаций.

Всего лишь пять оптических фирм, принявших участие в работе этой выставки, разрабатывают и изготавливают гризмы (см. таблицу), это:

- АО «НПО ГИПО» (в составе Холдинга АО «Швабе»), Россия [4];

- Fraunhofer-Institut für Angewandte Optik und Feinmechanik IOF (Фраунгоферовский инсти- тут прикладной оптики и точной механики), Германия [5];

- Wasatch Photonics, США [6];

- Carl Zeiss Spectroscopy GmbH, Германия [7];

- HORIBA France SAS (в составе международной компании "HORIBA»), Япония-Франция [8].

Гризмы представляют собой комбинацию "призма-пропускающая дифракционная решетка" либо склейку двух оптических призм (клиньев) и пропускающей дифракционной решетки, реализуя сочетание "призма- пропускающая дифракционная решетка-призма».

В гризме реализуется техническая возможность эффективного регулирования ее дисперсионных параметров за счет сочетания разных зависимостей дисперсионных свойств классической призмы (клина) и дифракционной решетки. Для одной рабочей длины волны возможно получить равенство угла преломления и угла дифракции, при этом гризма эквивалентна плоско-параллельной пластинке.

Пропускающая дифракционная решетка формируется, как правило, на одной (иногда на двух) плоской (или реже на криволинейной - цилиндрической) функциональной поверхности призмы (оптического клина). Сами эти поверхности призм (оптических клиньев) могут представлять собой в меридиональном сечении как грань-гипотенузу, так и грани-катеты. 
Формообразование пропускающей дифракционной решетки на гранях призмы (оптических клиньев) осуществляется при помощи следующих технологий:

- голографической, изготавливая объемнофазовую пропускающую голограммную дифракционную решетку в слое бихромированной желатины;

- голографической с последующим ионным травлением дифракционной структуры, получая в этом процессе рельефно-фазовую пропускающую голограммную дифракционную решетку в слое фоторезиста;

- электронно-лучевой литографии с последующим ионным травлением дифракционной структуры на плоско-параллельной пластинке из плавленого кварца, получая при этом бинарную рельефно-фазовую пропускающую решетку, а затем с последующим соединением этой пластинки с призмой;

- нарезной, получая дифракционную структуру непосредственно в материале призмы (стекле) с помощью специального алмазного резца;

- копированием дифракционной структуры с решетки-матрицы, в слое эпоксидной смолы, нанесенной на функциональную поверхность призмы.

Техника дифракционных решеток таит в себе большой потенциал возможностей.

\section{СПИСОК ЛИТЕРАТУРЫ:}

1. Герасимов Ф. М., Яковлев Э.А Дифракционные решетки / Современные тенденции в технике спектроскопии. - Новосибирск: Наука. 1982; 24-94.

Gerasimov F. M., YAkovlev E. A. Difrakcionnye reshetki / Sovremennye tendencii v tekhnike spektroskopii. - Novosibirsk: Nauka. 1982: 24-94.

2. Павлычева Н. К. Спектрапьные приборы с некиассическими дифракционными решетками. - Казань: Изд-во КГТУ. 2003.

Pavlycheva N. K. Spektral'nye pribory s neklassicheskimi difrakcionnymi reshetkami. Kazan': Izd-vo KGTU. 2003.

3. Мельников А. Н. Технологии формообразования светосильных дифракционных оптических элементов на основе использования делительной техники маятникового типа. Фотоника. 2019; 13(5): 468-475.

Mel'nikov A. N. Tekhnologii formoobrazovaniya svetosil'nyh difrakcionnyh opticheskih elementov na osnove ispol'zovaniya delitel'noj tekhniki mayatnikovogo tipa. Fotonika. 2019; 13(5): 468-475.

4. URL: http://shvabe. com/about/company/gosudarstvennyyinstitut-prikladnoy-optiki/produktsiya-gipo/opticheskie-materialy. Shvabe Holding JSC / NPO GIPO JSC / Optical component base catalog / Product catalog.

5. URL: http://www.fraunhofer.de. Fraunhofer-Institut für Angewandte Optik und Feinmechanik IOF/.

6. URL: https://wasatchphotonics.com. Wasatch Photonics / Product Catalog.

7. URL: https://www.zeiss.com/spectroscopy. Carl Zeiss Spectroscopy $\mathrm{CmbH}$ / Product Catalog.

8. URL: https://www.horiba.com/en_en/products/detail/action/show/Product/ gratings-for-astronomy-1816/. HORIBA / Product Catalog.

\section{Что в имени тебе моем? Первый рентгеновский источник, открытый ART-XC/SRG}

После продолжительного периода калибровок телескоп ART-XC на борту орбитальной обсерватории "Спектр-РГ" приступил к выполнению ранней научной программы. И в первом же сканирующем наблюдении балджа (центрального "утолщения") Галактики удалось обнаружить новый рентгеновский источник названный SRGA J174956-34086 (SRGA - источник обсерватории SRG, открытый телескопом ART-XC).

На всем небе известно около миллиона рентгеновских источников. Около сотни из них имеют свои собственные имена: "Быстрый барстер», «Великий аннигилятор» и.т.п., а все прочие называются единообразно - короткая аббревиатура в честь обсерватории, которая первой открыла этот источник, и координаты, обычно в экваториальной системе. Так и получаются имена типа CRS1915+105 - источник обсерватории "Гранат», с координатами 19 часов 15 минут прямого восхождения и 10 градусов склонения.

Впрочем, в рентгеновской астрономии открыть новый источник - это, как правило, лишь первый шаг на длинном и тернистом пути определения его физической природы. Он может оказаться как далеким квазаром, свет от которого добирался до нас многие миллиарды лет, так и близкой звездной системой с компактным объектом - нейтронной звездой или черной дырой. Чтобы решить подобную загадку, астрофизики стараются сначала максимально хорошо локализовать найденный объект, а потом осмотреть это место телескопами, работающими на других длинах волн - в радио-, оптическом, инфракрасном или гамма-диапазонах. Так, ничем не примечательная түсклая звездочка, видимая только в большой телескоп может оказаться ярчайшим на всем небе объектом, если посмотреть на нет рентгеновскими «глазами».

Для того, чтобы точнее локализовать обнаруженный объект, было выполнено короткое наблюдение на другом космическом рентгеновском телескопе - XRT обсерватории Swift имени Нейла Герельса, обладающем лучшим угловым разрешением. В мягких рентгеновских лучах SRCA $1174956-34086$ оказался тусклее, чем в жестких, что обычно встречается у источников, расположенных за облаками межзвездного газа и пыли, что, впрочем, не помешало XRT определить его координаты с точностью в несколько секунд дүги. В данных инфракрасного обзора WV в области локализации источника оказались две достаточно яркие звезды.

Теперь предстоит работа по получению их оптических спектров и определению, может ли какая-нибудь из них быть источником рентгеновского излучения, которое увидел ART-ХC, или нүжно искать другие, более слабые объекты. Это, однако, дело будущего, а свой след в каталогах рентгеновских источников ART-ХC уже оставил. Группа телескопа ART-ХC благодарит команду Swift за выполненные наблюдения.

По мamepuanam: http://press.cosmos.ru 


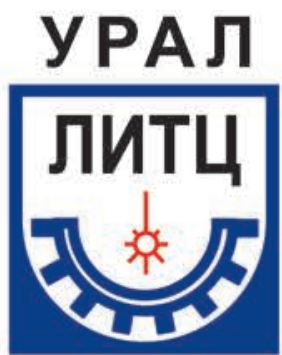

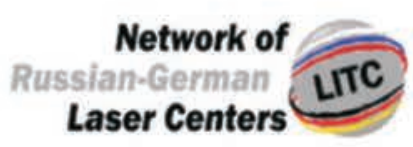

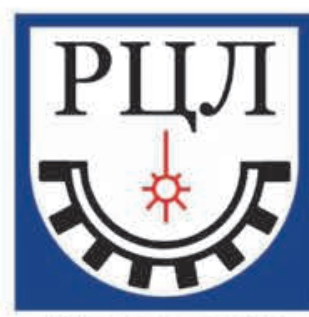

Основан в 1997
Регцональный центр

лазерных технологий

\section{Лазерная обработка металла. Наши технологии - Ваш успех!}

Предприятие полного цикла.

Предоставляет весь комплекс услуг от дизайна до опытного изделия и постановки на серию, на основе лазерных технологий по: 3D резке, сварке, термоупрочненин, наплавке, а также перфорации, механообработке, изготовлению высокоточных крупногабаритных конструкций из титановых сплавов с предъявлением представителю заказчика.

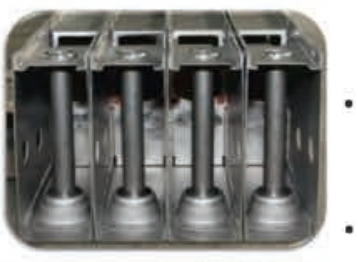

\section{услуги:}

3D лазерная резка - (титановые и алюминиевые сплавы, конструкционная и нержавеющая сталь (оищиной до 80 мм.)

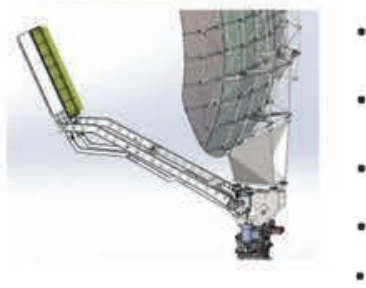

3D лазерная сварка (глубина сварноге بва - до 10 мм.);

- перфорация листового и трубного ороката;

3D лазерное поверхностное термбуйрочнение деталей;

- лазерная наплавка (в т.ч. восстановление форм и штампов);

высокоточная гибка;

- механообработка;

Изготавливаемая продукция:

корпусные детали, изделия для предприятий оمК,

металлургических и машиностроительных предприятий, РЖД,

строительных и монтажных организаций;

изделия для авиационной промышленностИосАтома;

крупногабаритные высокоточные метапябюностукции весом до 15 тонн.
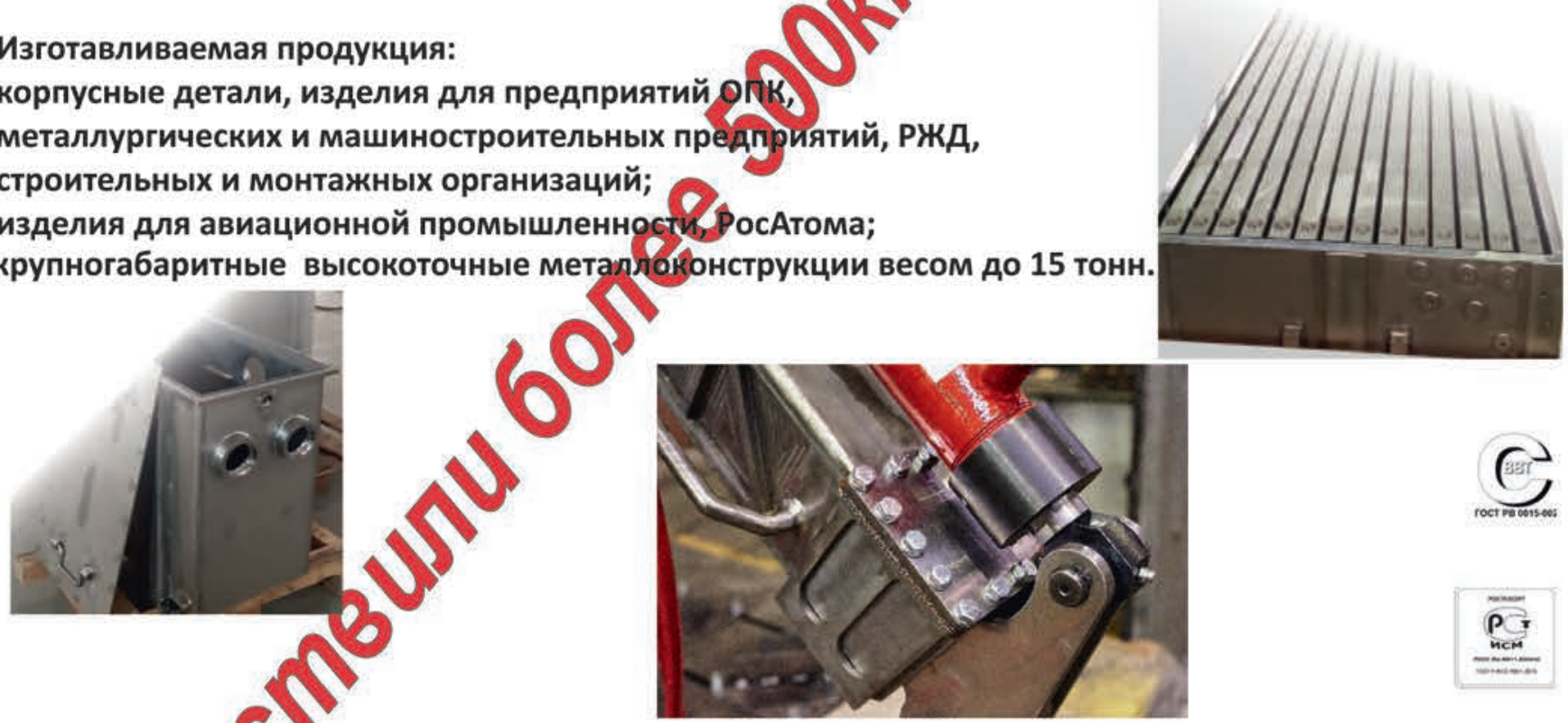

ЗАО «РЦЛТ» ВСегда открыто для сотрудничества с предприятиями, заинтересованными во внедрении современңых технологий в производство, высокая точность и качество работ которых обеспечивают конкурентоспособность продукции, в том числе и импортозамещение.

гекатеринбург, ул. Фронтовых Бригад, 18

8800550660 9, +7 (343) 272-30-80

Москва, ул. Большая Почтовая, 22

mail@ural-lazer.ru

рцлт.рф 